This item was submitted to Loughborough's Research Repository by the author.

Items in Figshare are protected by copyright, with all rights reserved, unless otherwise indicated.

\title{
Smart multi-terminal DC $\mu$-grids for autonomous zero-net energy buildings: implicit concepts
}

\section{PLEASE CITE THE PUBLISHED VERSION}

http://dx.doi.org/10.1109/ISGT-Asia.2015.7387184

\section{PUBLISHER}

(C) IEEE

\section{VERSION}

AM (Accepted Manuscript)

\section{PUBLISHER STATEMENT}

This work is made available according to the conditions of the Creative Commons Attribution-NonCommercialNoDerivatives 4.0 International (CC BY-NC-ND 4.0) licence. Full details of this licence are available at: https://creativecommons.org/licenses/by-nc-nd/4.0/

\section{LICENCE}

CC BY-NC-ND 4.0

\section{REPOSITORY RECORD}

Gonzalez-Longatt, Francisco M., Bharat Singh Rajpurohit, and Sri Niwas Singh. 2019. "Smart Multi-terminal DC M-grids for Autonomous Zero-net Energy Buildings: Implicit Concepts”. figshare. https://hdl.handle.net/2134/20511. 


\section{Smart Multi-Terminal DC $\mu$-grids for Autonomous Zero-Net Energy Buildings: Implicit Concepts}

\author{
Francisco Gonzalez-Longatt \\ Loughborough University \\ School of Electric, Electronic and \\ Systems Engineering \\ Loughborough, United Kingdom \\ fglongatt@fglongatt.org
}

\author{
Bharat Singh Rajpurohit \\ School of Electrical \& Computer Sc. \\ Indian Institute of Technology Mandi \\ Himanchal Pradesh \\ bsr@iitmandi.ac.in
}

\author{
Sri Niwas Singh \\ Department of Electrical Engineering \\ Indian Institute of Technology \\ Kanpur, Kanpur, India \\ snsingh@,iitk.ac.in
}

\begin{abstract}
A decarbonized society involves people living and working in low-energy and low-emission buildings. An a smart multi-Terminal DC $\mu$-grids interconnecting several autonomous zero-net energy buildings allow the transition to a decarbonized economy, however, involves several challenges. This paper describes the interactions between the intrinsic concepts related to development of a smart multi-terminal DC $\mu$-grids for autonomous zero-net energy buildings. Each individual concept provides several advantages but also create several colliding restrictions with other, this paper connects all concepts together considering interactions in other to maximize the total benefit. Also, discussions about the feasibility and impact of the individual concepts on the whole interaction are included.
\end{abstract}

Index Terms-DC, Electrical Storage System (EES), micro-grid, nano-grid, zero-net energy buildings.

\section{INTRODUCTION}

Challenges of future electricity networks are expected to growth and threatening to global security and prosperity. A general consensus about them includes [1]: (i) climate change, (ii) system security and (iii) economy globalization. The situation is complex because resources across the world are becoming scarce and the need for sustainable growth is increasingly important [1]. As a part of a national climate change strategy governments around the world are propitiating thoughtful efforts toward to become sustainable and decarbonised economies. The evolution to a decarbonised economy comprises three main aspects [1]: (i) developing energy efficiency measures, (ii) developing renewable energy capabilities and (iii) to deal with adaptation needs arising due to climate change. Energy efficiency is one of the key factors on migrating to a decarbonised economy, i.e. moving to a lowcarbon society. European Union (EU) is expecting to use around 30\% less energy in 2050 than in 2005. A decarbonised society involves people living and working in low-energy, low-emission buildings, including intelligent heating and cooling systems, and other low energy and high efficiency energy services (transportation, etc.).

This work was supported in part by British Council under the UKIERI, under grant DST/INT/UK/P-61/2014.
There is a huge prospect to optimise the energy use of both domestic and business customers. Households and businesses would take advantage of more secure and efficient energy including two important benefits: reducing energy bills while at the same time, delivering a more sustainable society. There are several initiatives around the world in order to develop very low energy buildings [2-7].

EU is enforcing the development of Nearly Zero-Energy Buildings (nZEB), according to article 9 of the Directive 2010/31/EU [8], "Member States shall ensure that by 31 December 2020 all new buildings are nearly zero-energy buildings; and after 31 December 2018, new buildings occupied and owned by public authorities are nearly zeroenergy buildings" [8]. Also, that EU directive define the nZEB as "a building that has a very high energy performance. The nearly zero or very low amount of energy required should be covered to a very significant extent by energy from renewable sources, including energy from renewable sources produced on-site or nearby" [8]. UK was the first country in the world to create a national legal framework for tackling climate change, the Climate Change Act [9] was introduced in 2008, creating a long-term legally-binding framework for coping with the climate change. It sets a target of reducing the net UK carbon account for all six Kyoto greenhouse gases by $80 \%$ compared to 1990 levels by 2050 , with a reduction of at least $34 \%$ by 2020 . Also, UK is one of the first countries in the world to have committed to research and development on nZEB.

In December 2006, the UK's government committed that from 2016 all new homes would be 'zero carbon' and introduced the Code for Sustainable Homes (CSM), a code against which the sustainability of new homes could be rated. This commitment was affirmed in the Building a Greener Future: Policy Statement in 2007 which proposed progressive tightening of the building regulations to achieve the 2016 goal, first by $25 \%$ in 2010 and then by $44 \%$ in 2013 . However, the CSM was discontinued as a separate code on 27 March 2015 and the UK government proposed to consolidate housing regulations and standards, incorporating the $\mathrm{CSH}$ standards into Part L of the Building Regulations. Several world class 
universities in UK have developed extensive research in nZEB considering varieties of approaches, i.e. market interaction, eco-architecture, etc. In March 2014, a consortium of one UK and two Indian universities was created: Loughborough University from the UK side and Indian Institute of Technology (IIT) Mandi and IIT Kanpur, from the Indian side. The consortium created a research project titled "Smart MultiTerminal DC $\mu$-grids for autonomous Zero-Net Energy Buildings". This two year project is successfully founded (DST/INT/UK/P-61/2014) by the UK India Education and Research Initiative (UKIERI) and Department of Science and Technology (DST), India. This paper is a first step disseminating some preliminary findings on the research project regarding involved concepts together considering interactions in other to maximize the total benefit.

This paper describes the interactions between the intrinsic concepts related to development of a smart multi-terminal DC $\mu$-grids for autonomous zero-net energy buildings. The paper is organized as follows: Section II briefly describes the research project and Section III explains the intrinsic concepts related to the development a smart multi-terminal DC $\mu$-grids for autonomous zero-net energy buildings. Section IV concludes.

\section{PROJECT DESCRIPTION}

The research project, named "Smart Multi-Terminal DC $\mu$ grids for autonomous Zero-Net Energy Buildings", started in March 2014. The main objective of that research project is to create a smart multi-terminal DC micro-grid capable to enable the development of autonomous zero net energy building.

This investigation is intended to facilitate India and UK transition to a low-carbon sustainable electricity the supply system for both urban and rural scenarios. The research plan is designed to realise this aim through an innovative and highly collaborative research programme involving British and Indian partners, which is mutually enriching and beneficial to both the countries. The main objectives of the research project are as follow:

1. To develop a shared cross-disciplinary vision and project requirements for a smart multi-terminal DC micro-grid (MTDC $\mu \mathrm{g}$ ) systems to enable $100 \%$ autonomous zero net energy building (aZNEB) for representative urban and rural areas in India and the UK;

2. To develop strategies, algorithms, models in order to define interactions of technologies, resources, communication systems and stakeholders in smart MTDC $\mu \mathrm{g}$.

3. To develop functional specifications, strategies, new functions and algorithms to ensure an adequate, secure and cost-effective MTDC $\mu \mathrm{g}$ design, operation and management under the vision of a $100 \%$ aZNEB. A flexible design approach will be used, and an agentbased modelling framework to facilitate the transition to a low-carbon sustainable electricity supply system under considerations of urban and rural scenarios.
4. To develop an architecture and information model suitable for the smart MTDC $\mu$ g concept developed.

5. To carry out simulations and tests using laboratory-based simulations, to test and validate the most promising solution and provide project outcomes. Results of this testing and validation stage will provide capacity building, training and experimentation. Considerations about business models and institutional arrangements for practical implementation will be considered.

6. To disseminate and exploit the research outputs and results. This involves promoting the creation of a framework for the effective exploitation of the results considering different levels: local, sectoral, regional, national and European. The developed framework must have synergy with the communication activities and improve the research capacity through a two-way collaboration between partners and a training programme; and to engage in wider dissemination of the findings.

The main aim of this research project is to create a Smart MTDC $\mu$ g capable to enable a successful $100 \%$ aZNEB. This smart MTDC $\mu$ g design will consider the main aspects of the context in the case of rural and urban areas of the UK and India, and enabling the transition to a low-carbon sustainable electricity supply system. In order to achieve the general objective several specific objectives are defines based on an activity-procedure approach and it defines the scientific keywords: Vision $\rightarrow$ Integration $\rightarrow$ Reliability $\rightarrow$ Proof $\rightarrow$ Understanding. As consequence six specific objectives are defined: (1) Vision: To develop a shared and crossdisciplinary vision and project requirements; (2) Interaction: To develop strategies, algorithms and models in order to define interactions of technologies, resources, communication systems and stakeholders; (3) Reliability: To develop functional specifications, strategies, new functions and algorithms to ensure fulfil the project vision is fulfilled; (4) Reliability: To develop an architecture and information model suitable for the smart MTDC $\mu$ g concept developed, (5) Proof: To carry out simulations and tests using laboratory-based simulations, to test and validate the most promising solution and provide project outcomes, (6) Understanding: disseminate and exploit the research outputs and results.

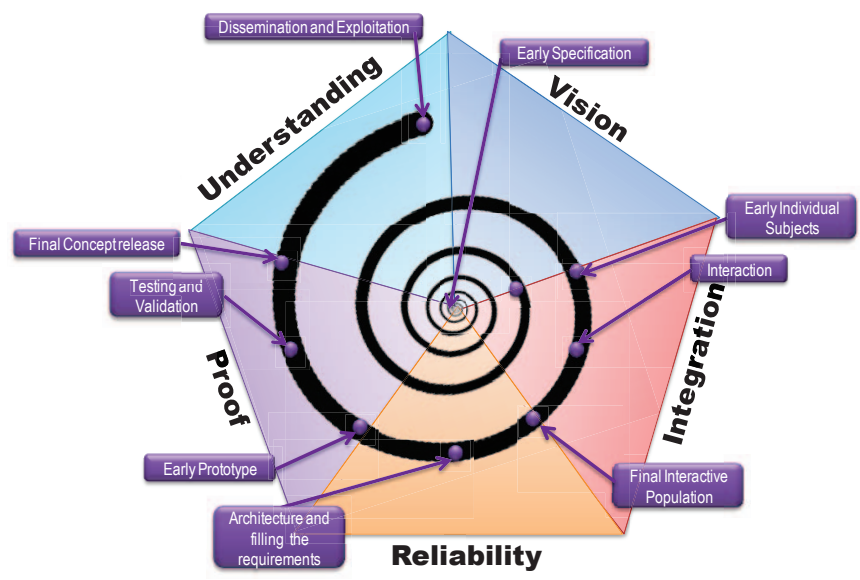


Figure 1. Approach and methodology for the research project.

An efficient methodology is required in order to allow the development and validation of the smart MTDC $\mu$ g concept capable of enabling a successful $100 \%$ aZNEB. Figure 1 depicts the schematic representation of the approach and methodology selected for this project. It is a constructivist methodology where the knowledge is constructed by a summative accumulation the information. Restraining project duration within a 24-month time frame dictates that multiple Work Package (WP) of experts will work in parallel, interfacing with each other regularly in order to exchange input and feedback for further work. The proposed project plan is closely related to the methodology adopted for the development and validation of the Smart MTDC $\mu$ g concept capable to enable $100 \%$ autonomous ZNEB. There are five work packages: four are for the technical research and development (WP1 to WP4), one is of demonstration of results (WP5) and one for dissemination (WP6). Figure 2 shows the relationships among of all the WPs.

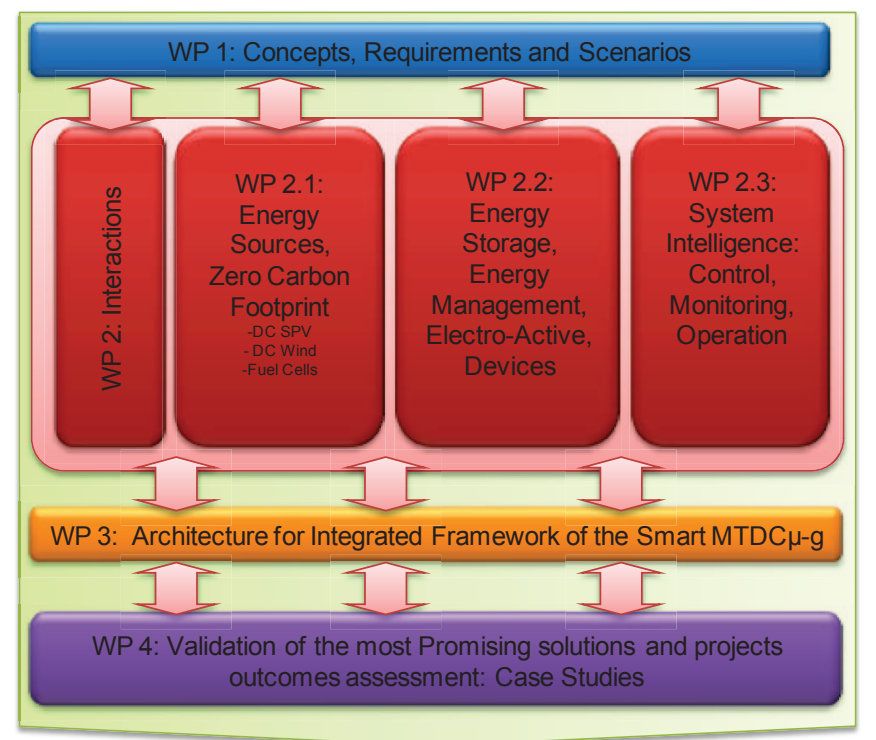

WP 5: Capacity Building, Dissemination and exploitation

Figure 2. Schematic of Relationship among all WP for the research project.

\section{IMPLICIT CONCEPTS}

Developing a smart multi-Terminal DC $\mu$-grids for autonomous zero-net energy buildings is a challenge, where several individual concepts are connected together in order to maximize the total benefit. The Smart MTDC $\mu$ g concept is a key component to create a building with zero net energy consumption and zero carbon emissions annually, known as ZNEB. ZNEB completely independent of the electricity grid (off-grid) works solely with self-generated and distributed RES, it facilitate the goal of $100 \%$ sustainable generation and zero carbon emission, but also considering the modern use of electricity for other services (water, heat, communication, cooking, etc.). A ZNEBs can be operated independently from infrastructural support services as an autonomous buildings providing an excellent solution for the electrification of rural areas in developing countries an alternative for urban areas everywhere. There are several challenges to face in the realization of the mentioned integrated Smart MTDC $\mu \mathrm{g}$ : (i) Integrated design and operations planning considering nondispatchable RES with un-correlated primary source and constrained distributed energy storage systems, (ii) Real-time energy balance considering 100\% non-dispatchable RES (wind and solar power), (iii) Recovery energy consumption of electricity storage systems after a major contingency, (iv) Risk of blackout and large outages during adverse weather conditions, (v) Other emerging challenges related with technology and legal framework.

This section presents the main implicit concepts on the development of the smart MTDC $\mu$ g capable of enabling a successful $100 \%$ aZNEB (see Fig. 3). Also, discussions about the feasibility and impact of the individual concepts on the whole interaction are included.

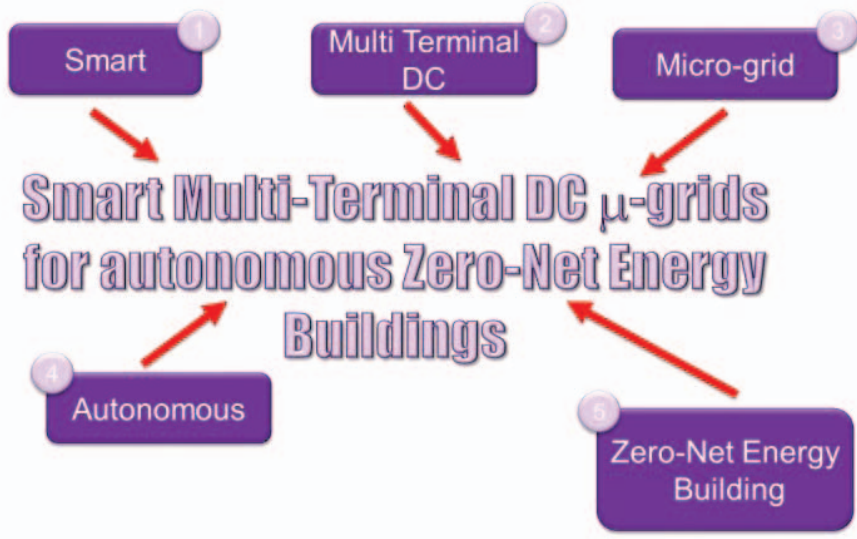

Figure 3. Concepts relaated to the development of a Smart Multi-Terminal DC $\mu$-grids for autonomous Zero-Net Energy Buildings.

\section{A. Smart Grid}

The term smart grid is not new, it has been in use since at least 2005, when it appeared in the article "Toward a Smart Grid" by Amin and Wollenberg [10]. There a very large number of smart grid definitions around the world [11], [12], but there is not an universal definition (several typical factor are common on them). The Department of Energy \& Climate Change and Ofgem, in UK, consider the smart grids as mechanism to enable new sources of energy and new forms of demand [13]. The smart electricity grid is intended to develop and support an efficient, timely transition to a low carbon economy to help the UK meet its carbon reduction targets, ensure energy security and wider energy goals while minimising costs to consumers.

In this project, a particular concept of smart grid is assumed based on the most common understanding about the basic features for a smart grid: (i) Self-Healing capacity in order to correct problems at early stages (resilience feature), (ii) increased levels of interactions between agents (consumers, markets, etc.), (iii) optimized operation and control ensuring the best use of resources, (iv) highly predictive operation to prevent emergencies, (v) Distributed assets and information and integrated to merge all critical 
information, and (vi) Enhanced cyber-physical security from threats from all hazards. In this project, the phrase smart grid is used to characterize a cyber-physical system with three important components: Massive deployment in ICT and optimal deployment and use of intelligent systems. A first glance, the concept looks feasible, but it include some collusion with other concepts related to development of Smart MTDC $\mu$ g concept for an aZNEB.

\section{B. Autonomous System}

In this project, an autonomous system is a system designed to be operated independently from infrastructural support. Typical support services includes: electrical power grid, gas grid, municipal water systems, sewage treatment systems, storm drains, communication services in some cases, public roads. Eliminating dependence on the electrical power grid is relatively simple, but there are several implications on the short/long term secure operation of the system. Some authors dealing with biomass and biofuels have recognised a potential of going fully off-grid but growing all necessary food is a more demanding and time-consuming proposition

In this paper, connection of the classical ac power grid is not considered, as consequence the Smart MTDC $\mu$ g is fully off-grid. There are two main conditions for going fully offgrid [14]: (i) Long Term Energy Security - To be sure that the energy supply over a long period of time to cover the energy load during this period of time (or at least if it is not the case, to be able to get additional electrical energy to the micro-grid $(\mu \mathrm{g})$ without connecting to the grid (e.g., backup generator, good neighbours, etc.) and (ii) Enough Flexibility: To have adequate flexibility means in the $\mu \mathrm{g}$ (e.g., modulation of the demand, storage devices, etc.) for being able to balance at any time production of electricity with consumption. Prof Damien Ernst of University of Liege has proposed four possible options to go fully off-grid:

1. Over-dimension of Energy Supply: The PV installation could be sized for producing during the less sunny periods of the year, an amount of energy equal to the energy consumed during these periods). This option is allow a sensible decrease of storage costs.

2. Hydrogen-based storage devices that use electrolysis to produce hydrogen and fuel cells to generate electricity from hydrogen are much less expensive than batteries in smoothing out long-term fluctuations. Indeed, the price of the hydrogen reservoir only grows slowly with its capacity.

3. Reduce inter-seasonal fluctuations: The closer you get from the equator, the less this problem of inter-seasonal fluctuation of PV energy production is marked. For example, while in Belgium PV panels produce 3 times as much energy in the six sunniest months of the years than during the rest of the year, this factor drops to 1.8 in South of Spain. A better primary-energy assessment and forecast is a key factor on reducing the fluctuations and decreasing the size and cost of energy storage.

4. Outsourcing mobile consumptions: During the less sunny months, off-grid $\mu \mathrm{g}$ ' owners could charge their electrical car at work to reduce their consumption or even transfer energy at night from their car to the $\mu \mathrm{g}^{\prime}$ batteries.

The recent announcement by Tesla Motors of their new battery systems, the Tesla's Powerwall [15], $10 \mathrm{kWh}$ of storage with selling price of $\sim £ 2,300$ (US\$ 3,500 ) looks like an important changing driver on the paradigm followed on the development of electrical grids.

Tesla's Powerwall includes a rechargeable lithium-ion battery, a liquid thermal management system, a battery management system and a smart DC-DC converter for controlling power flow. As consequence, this is a pure-DC device, DC-AC inverter not included in this this electricity energy storage. This battery system is almost ready to be part of a Smart MTDC $\mu$ g providing a realistic solution to go fully off-grid.

\section{Multi-Terminal DC System}

In this project, the concept multi-terminal DC (MTDC) system is used to define a power network where three or more power converter become interconnected through the single dc voltage level. The MTDC is the core of the whole Smart MTDC $\mu \mathrm{g}$ concept and three different types of DC-DC power converters are considered: (i) classical diode rectifier, (ii) boot converter and (iii) bidirectional converters. Two voltage levels are considered in the design of the MTDC $\mu$ g, low voltage level is used for low power loads and high voltage is used for heavy duty load, power generation, energy storage and also for power interchange between members of the MTDC $\mu \mathrm{g}$ (see Fig. 4).

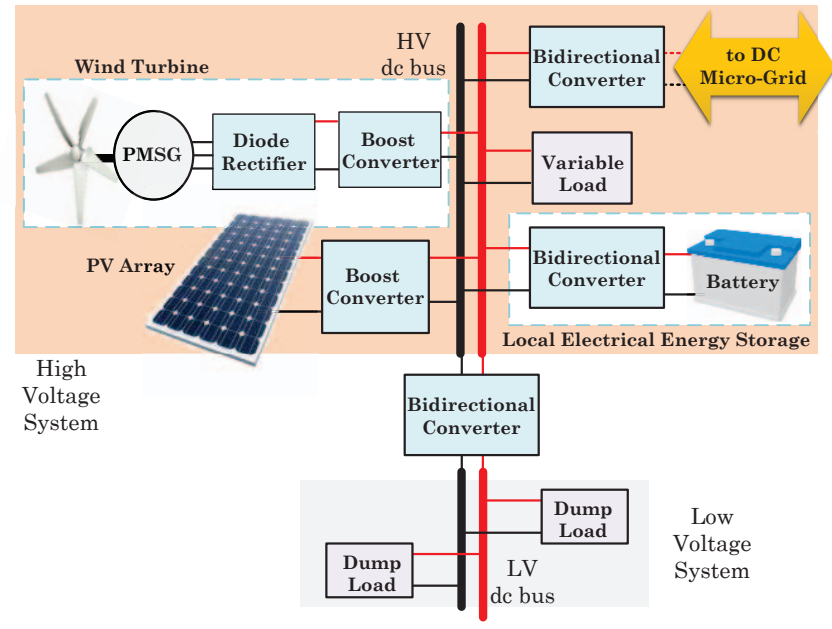

Figure 4. Schematic diagram of a Nano-grid representing a House inside the Smart MTDC $\mu \mathrm{g}$ concept.

\section{Micro-Grid}

The classical concept of $\mu \mathrm{g}$ consists of interconnected distributed energy resources (DER) capable of providing sufficient and continuous energy to a significant portion of internal load demand. An AC $\mu \mathrm{g}$ possesses independent controls, and intentional islanding takes place with minimal service interruption (seamless transition from grid-parallel to islanded operation. 
In this project, the smart MTDC $\mu$ g concept is based in the interaction of several interconnected nano-grids $(\mathrm{n}-\mathrm{g})$. In this paper the $\mathrm{n}-\mathrm{g}$ is a very small $\mu \mathrm{g}$, typically serving a single building or a single load. Fig. 3 presents schematic representation of a $\mathrm{n}$-g, where several components are included: power generation (PV and wind), local demand (dump loads and variable load) and local electrical energy storage (EES). The $\mathrm{n}$-g is connected to the other $\mathrm{n}$-gs using a high voltage DC distribution systems as show on Figure 4. The MTDC is the high power layer, where all energy interaction between $\mathrm{n}$-gs enable the Smart MTDC $\mu$ g concept. Local EES is located inside each n-g and a centralized EES or communal EES is included in order to enhance the energy security. Interactions between generation-demand-storage is one of the key components of the Smart MTDC $\mu$ g concept and it is related to key aspects of zero-net energy definition.

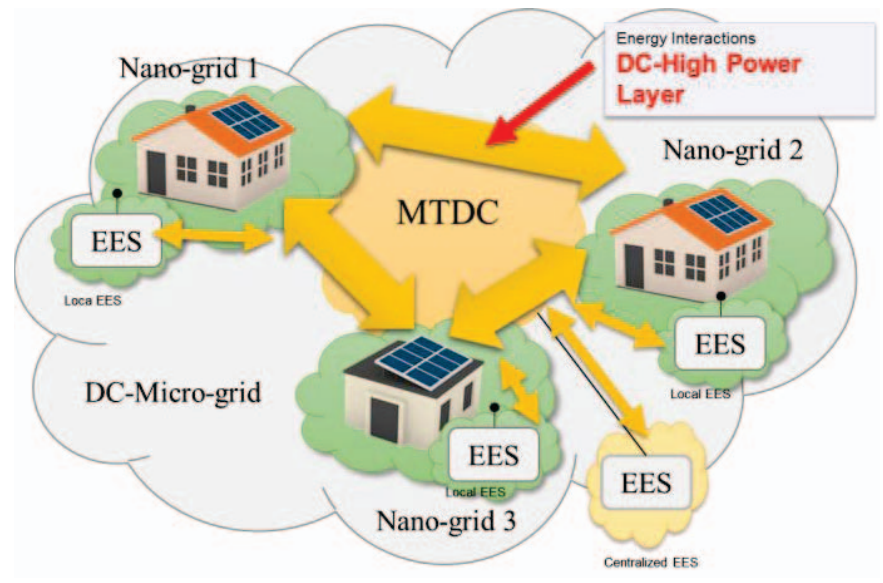

Figure 5. Schematic diagram of a DC multi-terminal micro-grid representing the core of the Smart MTDC $\mu \mathrm{g}$ concept.

\section{E. Zero-Net Energy Building}

There is a lack of a commonly agreed zero net energy building (ZNEB) definition, this issue has been already widely discussed on the international level [16]. There are several aspect involved in the definition: metric of the balance, balancing period, type of energy use included in the balance, type of energy balance, accepted renewable energy supply options, connection to the energy infrastructure, the requirements for the energy efficiency, the indoor climate and in case of grid connected ZEB for the building-grid interaction, etc. In this project, definitions related to on-grid options are discarded because the autonomous concept assumed in Section III.B. The four most used concepts on the ZNEB are presented below:

Net-Zero Site Energy: A site ZNEB produces at least as much energy as it uses in a year, when accounted for at the site.

$$
\sum_{i=1}^{\text {year }} E_{\text {production }}\left(t_{i}\right)=\sum_{k=1}^{\text {year }} E_{\text {comsumption }}\left(t_{k}\right)
$$

Net-Zero Energy Costs: The amount of money the utility pays the building owner for the energy the building exports to the grid is at least equal to the amount the owner pays the utility for the energy services

$$
\sum_{i=1}^{\text {year }} \operatorname{Total}_{\text {export }}\left(t_{i}\right)[\$]=\sum_{k=1}^{\text {year }} \operatorname{Total}_{\text {import }}\left(t_{k}\right)[\$]
$$

Net-Zero Energy Emissions: A net-zero emissions building produces at least as much emissions-free renewable energy as it uses from emissions-producing energy sources.

Net-Zero Source Energy: A source ZEB produces at least as much energy as it uses in a year, when accounted for at the source. Source energy refers to the primary energy used to generate and deliver the energy to the site. To calculate a building's total source energy, imported and exported energy is multiplied by the appropriate site-to-source conversion multipliers.

$$
\sum_{i=1}^{\text {year }} E_{\text {production }}\left(t_{i}\right)=\sum_{k=1}^{\text {year }} E_{\text {comsumption }}\left(t_{k}\right)
$$

In this project the most basic ZNEB model is used, it considers a building that produce as much energy as they consume. This concept provide an important requirement of the smart MTDC $\mu \mathrm{g}$ concept smart MTDC $\mu \mathrm{g}$ concept.

\section{CONCLUSIONS}

The key factors on the transition to a decarbonised economy are: energy efficiency, renewable energy and economic prosperity. This paper is a first step disseminating findings on the research project regarding involved concepts together considering interactions in other to maximize the total benefit. Development of a smart multi-terminal DC $\mu$-grids for autonomous zero-net energy buildings (aZNEB), which allow enhance the benefits of several already known concepts into a novel concept allowing the transition to a decarbonized economy. This paper describes the interactions between the intrinsic concepts related to development of a smart multiterminal DC $\mu$-grids for autonomous zero-net energy buildings. This paper is a step forward on the Developing a smart multi-Terminal DC $\mu$-grids for aZNEB is a challenge where several individual concepts are connected together in order to maximize the total systematic benefit. The Smart MTDC $\mu$ g concept is a key component but there (i) Integrated design and operations planning considering non-dispatchable RES with un-correlated primary source and constrained distributed energy storage systems, (ii) Real-time energy balance considering 100\% non-dispatchable RES (wind and solar power), (iii) Recovery energy consumption of electricity storage systems after a major contingency, (iv) Risk of blackout and large outages during adverse weather conditions, (v) Other emerging challenges related with technology and legal framework. This paper analyses five intrinsic concepts related to developing a smart multi-Terminal DC $\mu$-grids for aZNEB: Smart grid, multi-terminal DC, micro-grid, autonomous and zero-net building. Discussions about the feasibility and impact of the individual concepts on the whole interaction identify four key elements to create a successful smart MTDC $\mu \mathrm{g}$ : Integrated design and operations planning, site renewable strategies should be optimized using DC grid, optimally size and operated energy storage in order to enable 
the DC goes independent, system intelligence control, monitor, verify very-short time operation and mid/long term security.

\section{REFERENCES}

[1] F. Gonzalez-Longatt, "Frequency Control and Inertial Response Schemes for the Future Power Networks," in Large Scale Renewable Power Generation, J. Hossain and A. Mahmud, Eds., ed: Springer Singapore, 2014, pp. 193-231.

[2] COOPERaTE. (2013). COOPERaTE: Control and Optimization for Energy Positive Neighbourhoods. Available: http://www.cooperatefp7.eu/index.php/home.html

[3] DIMMER. (2013). DIMMER: District Information Modeling and Management for Energy Reduction. Available: http://dimmer.polito.it/

[4] EPBD. (2014). Towards 2020 - Nearly Zero Energy Buildings. Available: http://www.epbd-ca.eu/themes/nearly-zero-energy

[5] MESMERISE-CCS. (2014). MESMERISE-CCS: Multi-Scale Energy Systems Modelling Encompassing Renewable, Intermittent, Stored Energy And Carbon Capture And Storage Available: https://ukccsrc.ac.uk/resources/ccs-projects-directory/multi-scaleenergy-systems-modelling-encompassing-renewable

[6] SHINE-ZC. (2011). SHINE-ZC: Sustainable Housing Innovation Network of Excellence - Zero Carbon. Available: http://gtr.rcuk.ac.uk/project/DB712AB2-B58A-4947-AB0CC890F2BB1BCB
[7] ZenN. (2013). ZenN : Zero Energy Building Renovation. Available: http://www.zenn-fp 7.eu/

[8] EU. (2010). Directive 2010/31/EU of the European Parliament and of the Council of 19 May 2010 on the energy performance of building. Available: $\quad$ http://eur-lex.europa.eu/legalcontent/EN/TXT/HTML/?uri=CELEX:32010L0031\&from=EN

[9] U. S. L. Database. (2008). Climate Change Act 2008. Available: http://www.legislation.gov.uk/ukpga/2008/27

[10] S. M. Amin and B. F. Wollenberg, "Toward a smart grid: power delivery for the 21st century," Power and Energy Magazine, IEEE, vol. 3, pp. 34-41, 2005.

[11] DOE. (2013). Smart Grid | Department of Energy. Available: http://energy.gov/oe/services/technology-development/smart-grid

[12] EU. (2015). Smart Grids European Technology Platform. Available: http://www.smartgrids.eu/

[13] DECC, "Smart Grid Vision and Routemap," 2014.

[14] D. Ernst. (2014). Microgrids and their destructuring effects on the electrical industry. Available: http://orbi.ulg.ac.be/bitstream/2268/173600/1/ernst-microgrids.pdf

[15] TeslaMotors. (2015). Energy Storage for a Sustainable Home. Available: http://www.teslamotors.com/powerwall

[16] A. J. Marszal, P. Heiselberg, J. S. Bourrelle, E. Musall, K. Voss, I. Sartori, et al., "Zero Energy Building - A review of definitions and calculation methodologies," Energy and Buildings, vol. 43, pp. 971$979,4 / / 2011$. 